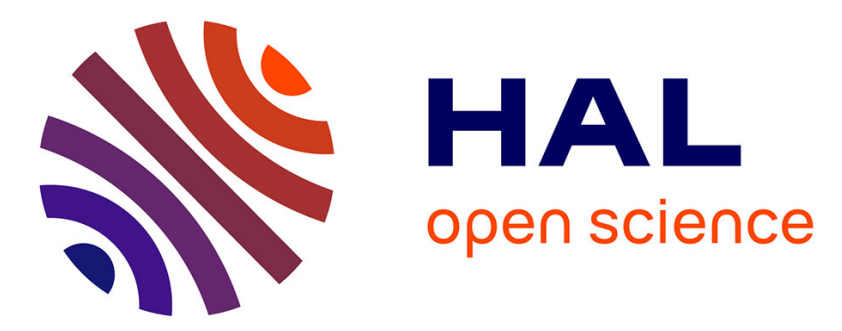

\title{
Activating both Halogen and Chalcogen Bonding Interactions in Cation Radical Salts of Iodinated Tetrathiafulavalene Derivatives
}

Maxime Beau, Olivier Jeannin, Sunhee Lee, Frédéric Barrière, Marc Fourmigué, Ie-Rang Jeon

\section{To cite this version:}

Maxime Beau, Olivier Jeannin, Sunhee Lee, Frédéric Barrière, Marc Fourmigué, et al.. Activating both Halogen and Chalcogen Bonding Interactions in Cation Radical Salts of Iodinated Tetrathiafulavalene Derivatives. ChemPlusChem, 2020, 85 (9), pp.2136-2142. 10.1002/cplu.202000500 . hal-02930252

\section{HAL Id: hal-02930252 https://hal.science/hal-02930252}

Submitted on 15 Sep 2020

HAL is a multi-disciplinary open access archive for the deposit and dissemination of scientific research documents, whether they are published or not. The documents may come from teaching and research institutions in France or abroad, or from public or private research centers.
L'archive ouverte pluridisciplinaire HAL, est destinée au dépôt et à la diffusion de documents scientifiques de niveau recherche, publiés ou non, émanant des établissements d'enseignement et de recherche français ou étrangers, des laboratoires publics ou privés. 
WILEY-VCH

\title{
Activating both Halogen and Chalcogen Bonding Interactions in Cation Radical salts of lodinated Tetrathiafulavalene Derivatives
}

\author{
Maxime Beau, ${ }^{[a]}$ Olivier Jeannin, ${ }^{[a]}$ Sunhee Lee ${ }^{[b]}$ Frédéric Barrière,${ }^{[a]}$ Marc Fourmigué ${ }^{*[a]}$ and le-Rang \\ Jeon $^{*[a]}$
}

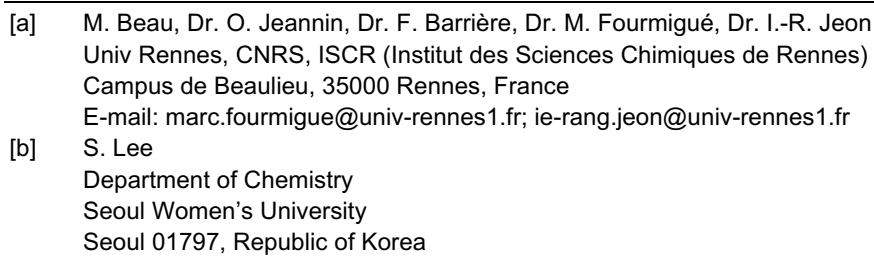

Supporting information for this article is given via a link at the end of the document.

\begin{abstract}
Halogen bonding (XB) interactions are investigated in cation radical salts of bis(methylthio)-5,5'-diiodotetrathiafulvalene (1). Electrocrystallization of 1 in the presence of $\mathrm{Bu}_{4} \mathrm{NCl}$ affords a $1: 1$ salt formulated as $(E-1) \mathrm{Cl}$. Particularly strong $1 \cdots \mathrm{Cl}^{-} \mathrm{XB}$ interactions are observed around the $\mathrm{Cl}^{-}$anion with the distances at $78 \%$ the sum of the van der Waals radii, a consequence of the XB charge activation in the cation radical. Moreover, the $\mathrm{Cl}^{-}$environment is complemented by two extra $5 . . . \mathrm{Cl}^{-}$chalcogen bonding $(\mathrm{ChB})$ interactions, an original feature among reported halide salts of TTF derivatives. Electrostatic potential calculations on the cation radical further demonstrate the efficient activation of the $S$ atoms of the 1,3-dithiole rings $\left(V_{s, \max }=87.2\right.$ $\mathrm{kcal} / \mathrm{mol})$, as strong as with the iodine atoms $\left(\mathrm{V}_{\mathrm{s}, \max }=87.9 \mathrm{kcal} / \mathrm{mol}\right)$. The radical cations form weakly dimerized stacks, as confirmed by the variable-temperature magnetic susceptibility and the weak conductivity $\left(4.8 \times 10^{-5} \mathrm{~S} \mathrm{~cm}^{-1}\right)$.
\end{abstract}

\section{Introduction}

Following the renewed interest for halogen bonding (XB) started in the beginning of the $1990 \mathrm{~s},{ }^{1}$ its involvement in material science has been particularity strong in the field of molecular conductors, essentially derived from cation radical salts of iodinated tetrathiafulvalenes (TTFs) (Scheme 1a). ${ }^{2}$ It was shown indeed that (partial) oxidation of iodinated TTFs leads to a strengthening of the $\sigma$-hole on the iodine atom, in the prolongation of the $\mathrm{C}_{T T F}-\mathrm{I}$ bond, to favor solid state structures where iodine establishes short contacts with the counter ion, be it monoatomic $\left(\mathrm{Cl}^{-}, \mathrm{Br}^{-}\right)$or polyatomic $\left[\left(\mathrm{ICl}_{2}^{-}, \mathrm{Ag}(\mathrm{CN})_{2}{ }^{-}\right){ }^{3}\right.$ Halometallate complexes such as $\mathrm{FeCl}_{4}{ }^{-}$or coordination complexes such as $\left[\mathrm{Ni}(\mathrm{mnt})_{2}\right]^{-},{ }^{4}$ were also used as XB acceptors in cation radical salts. This concept of charge activation upon electron transfer was later on convincingly investigated in solution ${ }^{5}$ and illustrated in a series of 2:1 charge transfer salts involving EDT-TTF- $I_{2}$ (in Scheme 1) and fluorinated tetracyanoquinodimethanes $\left(\mathrm{TCNQF}_{\mathrm{n}}, \mathrm{n}=0,1,2\right),{ }^{6}$ where stronger $1 \cdots \cdots N C X B$ were found in the charge transfer salt with $\mathrm{TCNQF}_{2}$ ( TTCNQF2 $=-1$ ) than in the neutral charge-transfer complex with TCNQ $(\rho T C N Q=0)$. The intermediate TCNQF salt exhibits a neutral-ionic transition under temperature ${ }^{7}$ and pressure. $^{8}$ Most reported examples of these iodinated TTFs involve derivatives bearing either one iodine atom (as in EDT-
TTF-I and EDO-TTF-I in Scheme 1), or two iodine atoms ortho to each other, on the same dithiole moiety (as in EDO-TTF-I $I_{2}$ and EDT-TTF- $I_{2}$ in Scheme 1), together with one single example of salt derived from TTF $-\mathrm{I}_{4}{ }^{9}$

(a)<smiles>[Y][Y]1=C2S/C(=C3/SC=C(I)S3)SC2=C([Y])CC1</smiles><smiles>[Y][Y]1:[Y](=O)c(I)c2sc(=C3SC(I)=C(I)S3)sc12</smiles>

(b)<smiles>FC(F)F</smiles><smiles>[Z17][Z17]1=CC(I)=CS1=c1scc(I)s1</smiles>

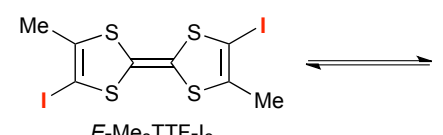<smiles>CC1=C(I)SC(=C2SC(C)=C(I)S2)S1</smiles>

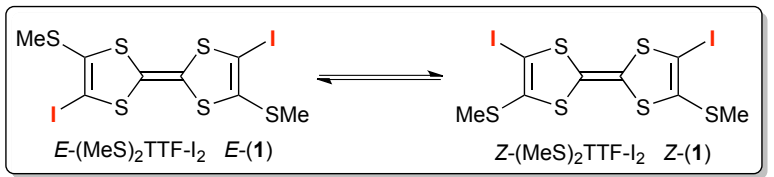

Scheme 1. lodinated TTFs (EDO-TTF = ethylenedioxytetrathiafulvalene; EDTTTF = ethylenedithiotetrathiafulvalene).

More recently, tetrathiafulvalenes bearing one iodine atom on each dithiole ring (Scheme 1b) have been investigated in cation radical salts, with the aim to stabilize one-dimensional structures linked by $\mathrm{XB}$, as in the complex salt formulated as $\left(\mathrm{Ph}_{4} \mathrm{P}^{+}\right)_{2}[E-$ TTF-I $]_{2}{ }^{+}\left(\operatorname{Re}_{6} \mathrm{Se}_{6}(\mathrm{CN})_{6}\right)^{3-}{ }^{10}$ One added complexity with these disubstituted molecules is the possibility offered to exist on both the $Z$ and $E$ forms, which are known, in TTF chemistry, to easily interconvert, either upon oxidation, ${ }^{11}$ or in the presence of traces of acid. ${ }^{12}$ It was indeed found that in its $2: 1$ bromide salt, $(Z, E)$ $\mathrm{Me}_{2}$ TTF- $\mathrm{I}_{2}$ crystallizes into segregated stacks made each of either the $Z$ and $E$ forms, and adopting each a different charge distribution. ${ }^{13}$ Following this approach, we turned our interest to another diiodosubstituted-(Z,E)-TTF, namely $(Z, E)-(\mathrm{MeS})_{2} \mathrm{TTF}^{\mathrm{I}} \mathrm{I}_{2}$ 
(1). We anticipated that the replacement of the -Me by the -SMe substituents will slightly increase the oxidation potential of the TTF while the flexibility of the thiomethyl group could modify the solubility of the salts. Indeed, it rapidly appeared that cation radical salts of 1 were difficult to obtain but we successfully isolated its chloride salt. We describe here our first results along these lines, investigating the solid state structure of this new salt, where not only strong halogen bonding $\left(1 \cdots \mathrm{Cl}^{-}\right)$interactions are identified but unexpectedly also chalcogen bonding $\left(\mathrm{S} \cdots \mathrm{Cl}^{-}\right)$ interactions.

\section{Results and Discussion}

\section{Synthesis.}

The preparation of 1 had been described earlier from the reaction of $(Z, E)-2,6(7)$-bis (methylthio)tetrathiafulvalene (BMT-TTF) with BuLi and 1,2-diiodoethane in ether. ${ }^{14}$ We have modified this procedure (Scheme 2) and reacted BMT-TTF with excess LDA followed by the addition of perfluorohexyliodide to provide 1 in $60 \%$ yield, after recrystallization from EtOAc. The starting compound BMT-TTF was prepared by adapting published procedures (See supporting information). The cyclic voltammogram of a dichloromethane solution containing 1 reveals the presence of two reversible redox processes centered at $E_{1 / 2}=$ 0.58 and $0.93 \mathrm{~V}$ vs SCE (Figure S1). Electrocrystallizations were performed by the galvanostatic oxidation of a solution containing 1 and a wide variety of different anions, halides $\left(\mathrm{Cl}^{-}, \mathrm{Br}^{-}, \mathrm{I}^{-}\right), \mathrm{PF}_{6}-$ and $\mathrm{AsF}_{6}{ }^{-}$, tetrahedral $\left(\mathrm{HSO}_{4}^{-}, \mathrm{ClO}_{4}^{-}, \mathrm{ReO}_{4}^{-}\right)$, linear $\left(\mathrm{I}_{3}^{-}, \mathrm{SCN}^{-}\right.$, $\left.\left[\mathrm{Ag}(\mathrm{CN})_{2}\right]^{-}\right)$. Crystals amenable to $\mathrm{X}$-ray diffraction were obtained with difficulties only in the presence of the $\mathrm{Cl}^{-}$anion to give a 1:1 salt, formulated as $(E-1) \mathrm{Cl}$.

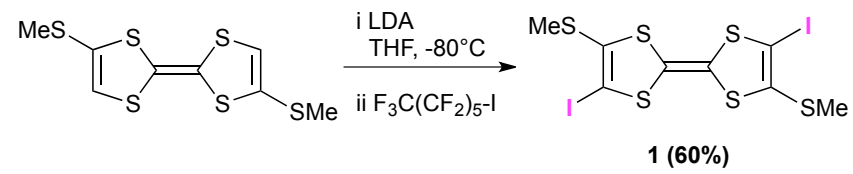

Scheme 2. Synthetic path to 1.

\section{Structural properties: Intermolecular interactions}

The neutral donor molecule $\mathbf{1}$ crystallizes in the monoclinic system, space group $\mathrm{P} 21 / \mathrm{c}$ with the molecule located on inversion center, hence in its $E$ conformation (Fig 1 a). It exhibits slight distortions from planarity with the dithiole rings folded along the S---S hinge by $7.3(3)^{\circ}$, generating a chair conformation, while the methyl substituents are pointing out of the mean conjugated plane (Fig. 1b). The molecules stack along the $a$ axis with a large planeto-plane distance of $3.69 \AA$ compatible with their neutral closedshell character (Fig. 1c). The iodine atom is not engaged in any $|\cdots|$ | halogen bonding and the shortest $\mid \cdots$. S contacts exceed 3.88 $\AA$, above the sum of van der Waals radii $(3.78 \AA) .{ }^{15}$

The chloride salt is obtained as very tiny needles from electrocrystallization of 1 in the presence of tetrabutylammonium chloride as electrolyte. It crystallizes in the monoclinic system, space group $\mathrm{P} 2 / \mathrm{n}$ with $\mathbf{1}^{+\cdot}$ cation in general position and two chloride anions, each of them located on a two-fold axis, hence the 1:1 stoichiometry. The molecule is essentially planar (including the methyl group) and adopts a $E$ conformation, as in its neutral state. Structural evolutions within the donor molecule, despite the low quality of the structure for $(E-1) \mathrm{Cl}$ (Table 1), confirms its oxidized character, featuring a lengthening of the $C=C$ double bonds and a shortening of the $\mathrm{C}-\mathrm{S}$ single bonds, compared to the neutral 1. As shown in Figure 2, the iodine atoms of the TTF are engaged in directional interactions with the chloride anion $\left(\angle \mathrm{C}-1 \cdots \mathrm{Cl}^{-}=174-175^{\circ}\right)$, with $1 \cdots \mathrm{Cl}^{-}$distances $(2.96-2.97$ $\AA)$ much shorter than the contact distance $(3.79 \AA)$ determined as the sum of iodine van der Waals radius $(1.98 \AA)$ and chloride ionic radius $(1.81 \AA)$, giving a reduction ratio $(R R)$ well below $0.8(0.78)$.
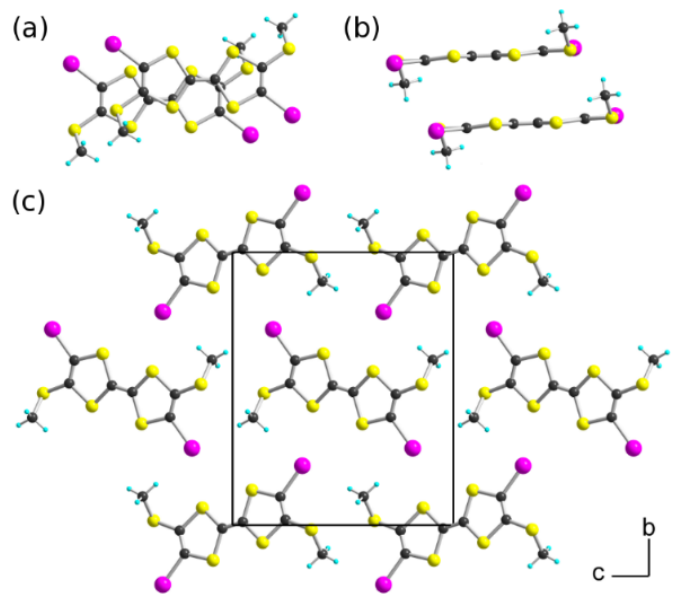

Figure 1. Structure of neutral 1 with (a) overlap pattern within chains running along a axis; (b) side view; (c) projection view along stacking axis a.

Table 1. Bond distances $[\AA]$ in the neutral 1 and oxidized TTF $1^{+\cdot} \cdot[a]$<smiles>C[13CH2]C1=C(I)[Se]C(=C2SC(C)=C(I)S2)S1</smiles>

\begin{tabular}{l|l|l|l|l|l|l}
\hline & $\mathrm{a}$ & $\mathrm{b}, \mathrm{b}^{\prime}$ & $\mathrm{c}, \mathrm{c}^{\prime}$ & $\mathrm{d}$ & $\mathrm{e}$ & $\mathrm{f}$ \\
\hline $\mathbf{1}$ & $1.32(1)$ & $1.779(6)$ & $1.757(7)$ & $1.306(10)$ & $1.752(8)$ & $2.080(7)$ \\
& & & & & \\
$\mathbf{1}^{+\cdot}$ & $1.40(7)$ & $1.74(5)$ & $1.71(4)$ & $1.35(7)$ & $1.73(4)$ & $2.11(4)$ \\
& & $1.70(5)$ & $1.75(5)$ & & & \\
\hline
\end{tabular}

[a] Bond distances were averaged considering a pseudo inversion center.

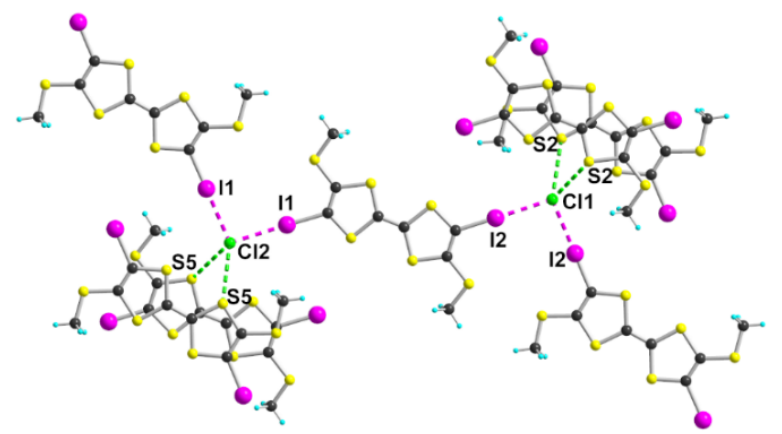

Figure 2. Details of the $\mathrm{XB}$ (pink dotted lines) and ChB (green dotted lines) interactions in $(E-1) \mathrm{Cl}$. 
This represents one of the shortest $1 \cdots \mathrm{Cl}^{-} \mathrm{XB}$ interaction reported so $\operatorname{far}^{16,17}$ and the shortest one involving iodinated TTFs. The chloride is interacting with two iodine atoms giving then a kind of $\mu_{2}$ "coordination" around the halide. We have collected in Table 2 the few examples of reported iodinated TTFs interacting with the $\mathrm{Cl}^{-}$anion. We note indeed the very strong XB found here, most probably due to the actual $1: 1$ stoichiometry of the salt since other reported examples are mixed-valence salts with an averaged +0.5 charge on each TTF. As a consequence, the effect of charge activation, which has been unambiguously demonstrated in solution $^{5}$ and in XB charge transfer salts, ${ }^{6}$ is enhanced here with a diiodo TTF bearing a +1 charge.

Table 2. Reported structural characteristics of halogen-bonded iodinated TTFs with the $\mathrm{Cl}^{-}$anion.

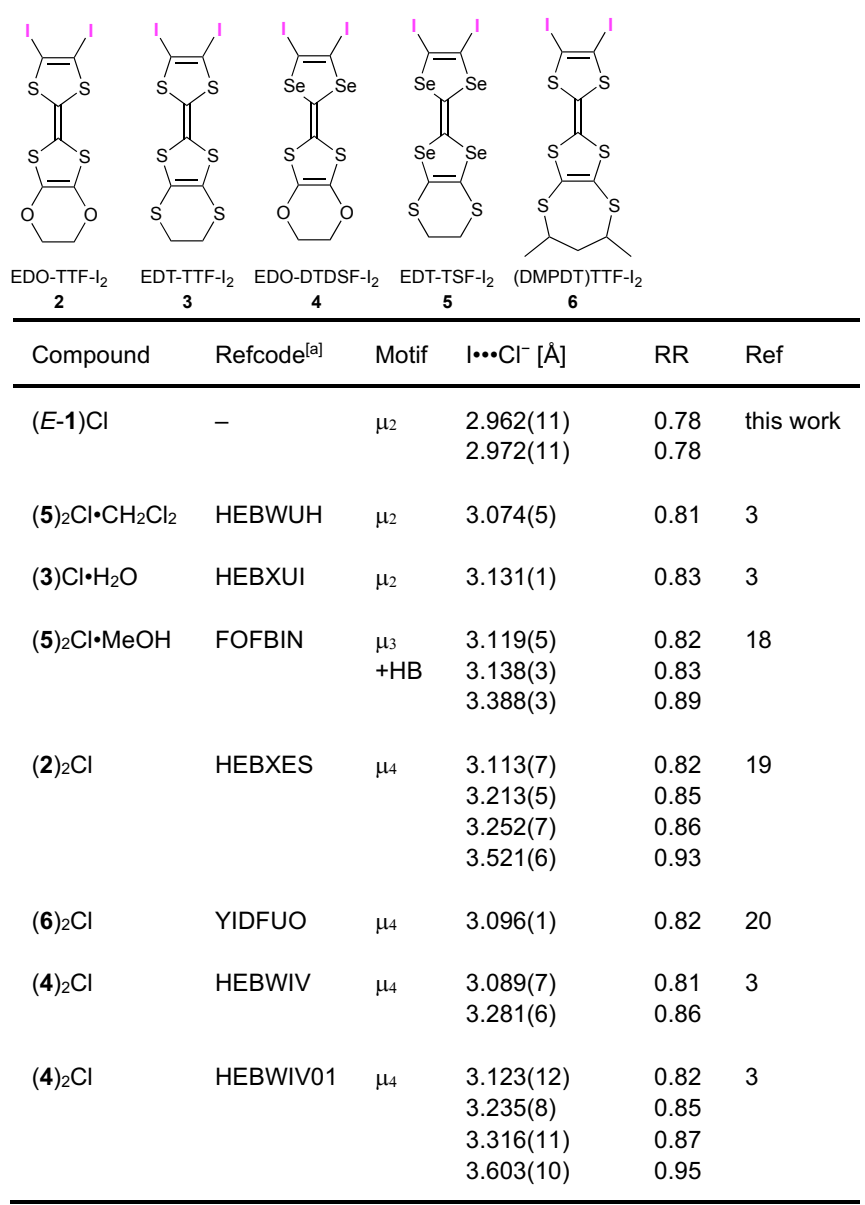

[a] CCDC refcode from CSD version 5.41 (November 2019).

Another very interesting feature of this salt is also highlighted in Figure 2 where we note that besides the iodine atoms, the chloride anion is also engaged in short sulfur $\cdots$ chloride contacts. The S $\cdots \mathrm{Cl}^{-}$distance amounts to $3.410(17)$ and $3.390(18) \AA$ for $\mathrm{S} 2 \cdots \mathrm{Cl} 1$ and $\mathrm{S} 5 \cdot \cdots \mathrm{Cl} 2$ respectively, which corresponds to a notable reduction ratio of 0.90 relative to the contact distance of $3.61=1.80(\mathrm{~S})+1.81 \AA\left(\mathrm{Cl}^{-}\right) \AA$. These two interactions, so-called chalcogen bonds, complement the coordination sphere of the chloride anion which adopts thus a $\mu_{4}$ geometry of a distorted tetrahedron. The chalcogen bonding interaction is indeed a recently-emerging $\sigma$-hole interaction, with numerous implications in crystal engineering, catalysis, molecular materials, and biochemistry. ${ }^{21}$

It is surprising at this stage that such chalcogen bonding interactions have not been observed more systematically in the huge set of cation radical salts derived from TTF molecules and their derivatives (TMTTF, EDT-TTF, BEDT-TTF; TMTTF = tetramethyltetrathiafulvalene; $\quad$ BEDT-TTF = bis(ethylenedithio)tetrathiafulvalene). Indeed, upon oxidation to the cationic state, it is expected that the sulfur atoms of the two dithiole rings of the TFF core will bear some partial positive charge able to interact with, for example, the chloride anion. A bibliographic survey of structurally characterized TTF's chloride salts gives, beside the iodinated compounds reported in Table 2, only a few examples. Several salts adopt the classical 2:1 stoichiometry (i.e. $\rho_{\mathrm{TTF}}=+0.5$ ), as in $(\mathrm{BEDT}-\mathrm{TTF})_{2} \mathrm{Cl} \cdot\left(\mathrm{H}_{2} \mathrm{O}\right)_{2},{ }^{22}$ $(\mathrm{EDO}-\mathrm{TTF})_{2} \mathrm{Cl} \cdot\left(\mathrm{H}_{2} \mathrm{O}\right)_{3},{ }^{23} \quad(t \mathrm{TTF})_{2} \mathrm{Cl} \quad(t \mathrm{TTF}=$ trimethylenetetrathiafulvalene $),{ }^{24}$ or $(o-D M T T F){ }_{2} \mathrm{Cl}(o-\mathrm{DMTTF}=o-$ dimethyltetrathiafulvalene).$^{25}$ Other mixed-valence salts, but with non-conventional stoichiometries include several BEDT-TTF salts such as (BEDT-TTF) ${ }_{3} \mathrm{Cl}_{2} \bullet\left(\mathrm{H}_{2} \mathrm{O}\right)_{2},{ }^{26}$ (BEDT-TTF $)_{5} \mathrm{Cl}_{3} \bullet\left(\mathrm{H}_{2} \mathrm{O}\right)_{5},{ }^{27}$ (BEDT-TTF) ${ }_{6} \mathrm{Cl}_{5} \cdot\left(\mathrm{H}_{2} \mathrm{O}\right)_{4},{ }^{28}$ together with the non-stoichiometric (TTF) $\mathrm{Cl}_{0.92}$ TTF salt. ${ }^{29}$ No salts with $\rho=+1$ is reported and only one salt with $\rho=+2$ is characterized, namely (BMDT-TTF) $\mathrm{Cl}_{2}$ (BMDT-TTF $=$ bis (methylenedithio)tetrathia-fulvalene). ${ }^{30}$ We have collected in Figure 3, representative structures of these salts. (a) (BEDT-TTF $)_{3} \mathrm{Cl}_{2}\left(\mathrm{H}_{2} \mathrm{O}\right)_{2}$

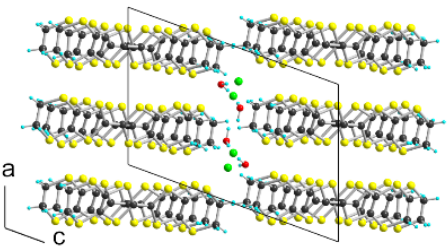

(c) (o-DMTTF $)_{2} \mathrm{Cl}$

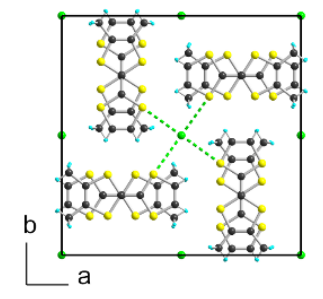

(b) (tTTF) ${ }_{2} \mathrm{Cl}$

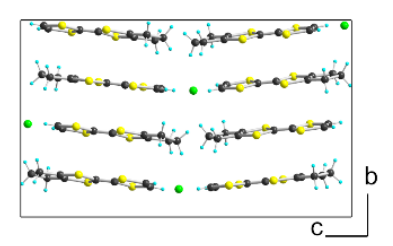

(d) (BMDT-TTF) $\mathrm{Cl}_{2}$

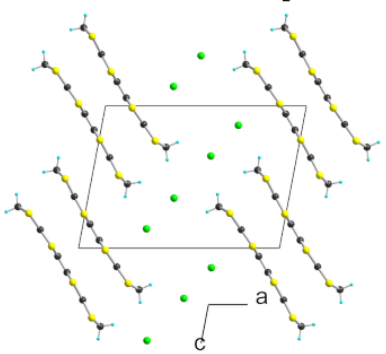

Figure 3. Representative examples of TTFs salts with $\mathrm{Cl}^{-}$anion. The green dotted lines in (c) indicate the presence of $\mathrm{S} \cdot \cdot \mathrm{Cl}^{-}$chalcogen bonds (See text).

It appears that in most examples (as in Figure 3a,b), the radical cations form 1D stacks and that these stacks interact sideways with adjacent ones, through the long molecular axis of the TTFs parallel to each other. As a consequence, $2 \mathrm{D}$ overlap interactions between TTF HOMOs in partially oxidized stacks are favored at the expense of the direct $\mathrm{S}^{+\delta} \cdot{ }^{\circ} \mathrm{Cl}^{-}$contacts. The chloride anions are found then interacting essentially with the hydrogen atoms located at the outer ends of the molecules, stabilized in a complex set of $\mathrm{C}-\mathrm{H} \cdots \mathrm{Cl}^{-}$hydrogen bonds $(\mathrm{HB})$. Such $\mathrm{HB}$ are also observed in the dicationic $(\rho=+2)$ salt $(B M D T-T T F) \mathrm{Cl}_{2}$ (Figure 
3d). The only rare situation where short $\mathrm{S} \cdot \cdot \mathrm{Cl}^{-}$contacts are found is the original quadratic structure observed in (o-DMTTF $)_{2} \mathrm{Cl}$ (Figure $3 \mathrm{c}),{ }^{25}$ where the chess-board organization of the strictly 1D stacks allows, besides the $\mathrm{C}-\mathrm{H} \cdot \cdot \mathrm{Cl}^{-}$contacts, for short $\mathrm{S} \cdot \cdots \mathrm{Cl}^{-}$chalcogen bond interactions. The $\mathrm{S} \cdot \cdots \mathrm{Cl}^{-}$distance amounts to 3.492(1) $\AA$ (RR = 0.94), notably weaker than those found here in $(E-1) \mathrm{Cl}(\approx 3.40 \AA, \mathrm{RR}=0.90)$. It follows that the $(E-$ 1) $\mathrm{Cl}$ salt reported here combines indeed strong and simultaneous halogen and chalcogen bonding around the $\mathrm{Cl}^{-}$anion in its $\mu_{4}$ environment. Overall, our initial motivation on replacing the $-\mathrm{Me}$ groups by the $-S M e$ substituents on the $(Z, E)-T T F-I_{2}$ led to the structural organization of its oxidized halide salts in a fully different way, including the absence of Z-isomers, which ultimately enables the activated core sulfur atoms to participate in the chalcogen bonding interactions.

\section{Electrostatic Surface Potential (ESP) calculations}

To further probe the experimentally observed activation of halogen and chalcogen bonding interactions in $(E-1) \mathrm{Cl}$, we have compared the presence and the magnitude of the $\sigma$-holes on the neutral molecule 1 and the oxidized salt $(E-1) \mathrm{Cl}$ via the calculation of the Electrostatic Surface Potential (ESP) on their optimized geometry (with Density Functional Theory using the B3LYP functional and the $6-31+G^{* *}$ basis set for all atoms and the LANLdp basis set for iodine). As shown in Figure 4, a directional $\sigma$-hole, represented by an intense blue region, is estimated along the elongation of the $\mathrm{C}-\mathrm{I}$ bond. The calculated maximum ESP value on the optimized geometry of the molecules increases from 30.3 to $87.9 \mathrm{kcal} / \mathrm{mol}(126.8$ to $367.8 \mathrm{~kJ} / \mathrm{mol}$ ) for the neutral and the oxidized one, respectively. The observed trend is consistent with what we have previously calculated for the mono-iodinated TTF derivative, $\mathrm{Me}_{3}$ TTF-I. ${ }^{31}$ Besides iodine atoms, the sulfur atoms of the dithiole moiety in the neutral molecule 1 exhibit negative ESP values, $-13.2 \mathrm{kcal} / \mathrm{mol}(-55.2 \mathrm{~kJ} / \mathrm{mol})$. Once oxidized, however, the cationic molecule exhibits positive ESP regions throughout the TTF core. Notably, the two sulfur atoms from the two dithiole rings provide a merged strongly electron deficient region in the middle with the estimated ESP value (87.2 $\mathrm{kcal} / \mathrm{mol}$ or $364.8 \mathrm{~kJ} / \mathrm{mol}$ ) as large as the one calculated for the iodine atom in $1^{+\cdot}$. It is worth noting that, although the calculated ESP value itself is as strong as the one at the iodine, the steric situation of the buried $\sigma$-hole between two dithiole rings may render the chalcogen bonding less efficient than the directional halogen bonding through the iodine. Overall, the theoretical calculation confirms the strong activation of both iodine and sulfur atoms of the TTF core in the oxidized salt $(E-1) \mathrm{Cl}$, consistent with the structurally observed strong and simultaneous halogen and chalcogen bonding.

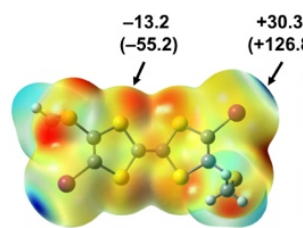

NEUTRAL

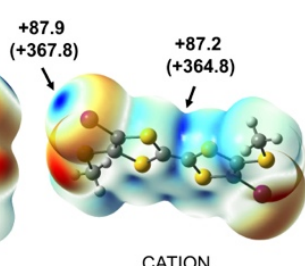

CATION
Figure 4. Molecular Electrostatic Surface Potential (ESP) mapped at the 0.001 $\mathrm{e}^{-} \mathrm{au}^{-3}$ isovalue for the neutral 1 and the cationic radical $\mathbf{1}^{+\cdot}$ with the magnitude of selected ESP values discussed in the main text in $\mathrm{kcal} / \mathrm{mol}$ (or $\mathrm{kJ} / \mathrm{mol}$ ). Note the different color scale set from the extrema at the lowest and highest values in each oxidation state; for the neutral $1(-15.2$ to $+30.3 \mathrm{kcal} / \mathrm{mol}$ or -63.6 to
$126.8 \mathrm{~kJ} / \mathrm{mol})$; for the cationic radical $1^{+*}(+48.8$ to $+87.9 \mathrm{kcal} / \mathrm{mol}$ or +204.2 to $+367.8 \mathrm{~kJ} / \mathrm{mol}$ ).

\section{Physical properties: Electric resistivity and magnetic susceptibility}

Another interesting point to discuss in $(E-1) \mathrm{Cl}$ is the relationships between its structure and its electronic properties, including conductivity and magnetism. As shown in Figure 5 , the $1^{+\cdot}$ radical cations stack along the $c$ direction. Within the stack, molecules are related to each other by a two-fold axis, giving then a small but present dimerized character to these chains. The absence of a strong dimerization let us infer that this compound could be semiconducting.

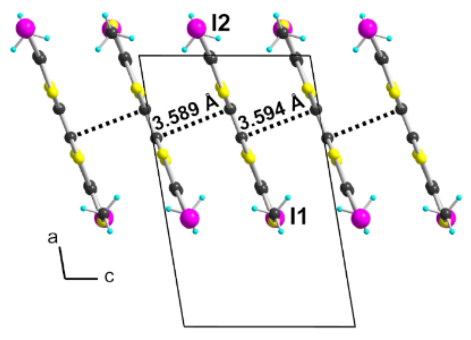

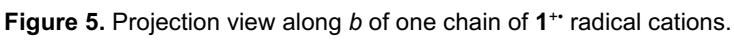

Variable temperature resistivity was measured on a pressed pellet of $(E-1) \mathrm{Cl}$ (Figure 6). Note that the powder X-ray diffraction pattern of the accumulated polycrystalline samples from the electrocrystallization is consistent with the simulated one from the single crystal X-ray diffraction data (Figure S2), confirming the bulk purity of the sample for the electric and the magnetic characterizations. The compound shows a room-temperature resistivity of $2.1 \times 10^{4} \mathrm{ohm} \cdot \mathrm{cm}$ and an activation behavior upon cooling. The activation energy between 170 and $270 \mathrm{~K}$ is estimated at $E_{\text {act }}=0.18 \mathrm{eV}$ based on $\rho=\rho_{0} \exp \left(E_{\mathrm{act}} / \mathrm{T}\right)$.

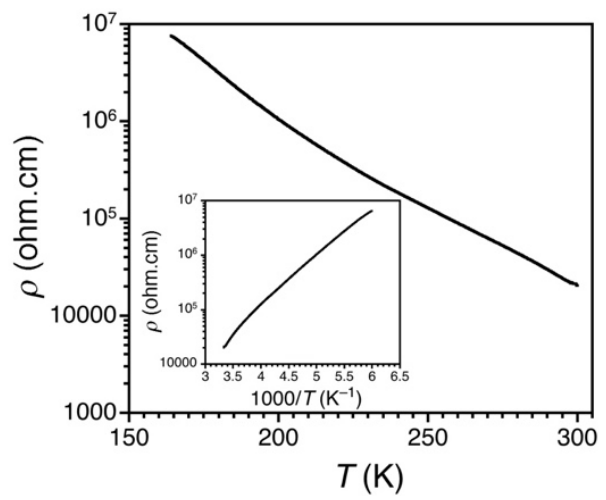

Figure 6. Temperature dependence of the resistivity for a pressed pellet of ( $E$ 1)Cl. Inset: a plot $\rho$ of $v s 1000 / T$ to highlight a linear activated regime.

To further probe the spin structure and the magnetic ground state of the compound, variable-temperature magnetic susceptibility was measured on a polycrystalline sample of $(E-1) \mathrm{Cl}$. As shown in Figure 7 , the spin susceptibility, $\chi$, gradually decreases from $0.00036 \mathrm{~cm}^{3} \mathrm{~mol}^{-1}$ at $300 \mathrm{~K}$ to $1.8 \times 10^{-4} \mathrm{~cm}^{3} \mathrm{~mol}^{-1}$ at $100 \mathrm{~K}$, before an abrupt increase at lower temperature due to a Curie-tail 
contribution presumably arising from magnetic defects and/or impurities. Based on the crystal structure and semiconducting behavior of the compound, one expects a one-dimensional localized regime where each donor bears a spin $1 / 2$ with a nonuniform spacing. Therefore, the thermal dependence of the susceptibility has been fitted with an alternating chain model with two interaction parameters $J$ and $\alpha J$ based on the following Hamiltonian, $\quad H=-2 J \sum_{i=1}^{n / 2}\left[S_{A_{2 i}} \cdot S_{A_{2 i-1}}+\alpha S_{A_{2 i}} \cdot S_{A_{2 i+1}}\right]$, which provides $J / k_{B}=-350 \mathrm{~K}$ and $\alpha=0.26$. Note that the fitting of the results with a uniform chain Bonner-Fisher model or a BleaneyBower singlet-triplet model was not successful to reproduce the experimental data. Overall, the magnetic data is also consistent with the crystal structure and the electric conductivity data. They are first a consequence of the 1:1 stoichiometry of the salt. Beside the dimerization of the chains and associated singlet ground state, the limited inter-chain interactions due to the bulky -SMe groups and the insertion of the $\mathrm{Cl}^{-}$anion in-between the chains (Figure 2 ) also contributes to this very weak conductivity.

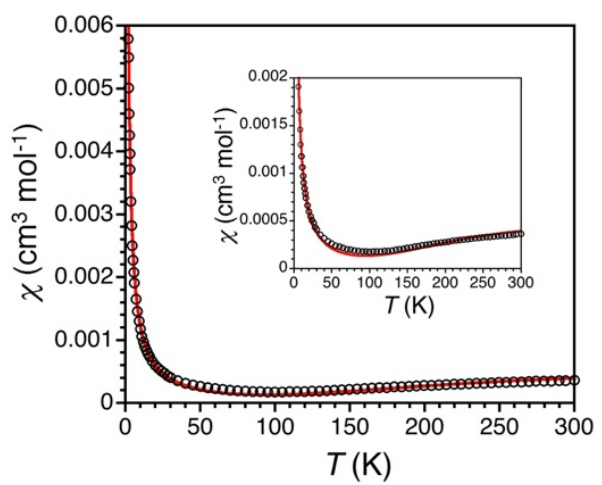

Figure 7. Variable-temperature dc magnetic susceptibility $(\chi=M / H$ per mole of compound) data for $(E-1) \mathrm{Cl}$ collected under an applied filed of $1000 \mathrm{Oe}$. The red solid curve is the fit to the data based on the alternating chain model described in the main text. Inset: a zoomed-in plot of the main figure.

\section{Conclusion}

An optimized preparation of bis(methylthio)-5,5' diiodotetrathiafulvalene (1), whose structure was also determined by $\mathrm{X}$-ray diffraction, allowed for electrocrystallization experiments in the presence of various anions. A 1:1 salt formulated as $(E-1) \mathrm{Cl}$ was isolated with $\mathrm{Bu}_{4} \mathrm{NCl}$. Particularly strong $1 \cdots \mathrm{Cl}^{-}$halogen bonding interactions are observed around the chloride anion with l... Cl- distances at $78 \%$ the contact distance, a consequence of the charge activation in the TTF cation radical $(\rho=+1)$. The $\mathrm{Cl}^{-}$ environment is complemented by two extra $\mathrm{S} \cdots \mathrm{Cl}^{-}$chalcogen bonding interactions, an original feature among reported halide salts of TTF derivatives. The cation radical in $(E-1) \mathrm{Cl}$ indeed shows strongly electron deficient zones at the iodine atoms as well as in between two sulfur atoms of each dithiole ring. Notably the calculated ESP value of the latter $(+87.2 \mathrm{kcal} / \mathrm{mol})$ is as large as that of the iodine $\sigma$-hole $(+87.9 \mathrm{kcal} / \mathrm{mol})$, confirming the efficient simultaneous activation of halogen and chalcogen bonding interactions observed in the structural analyses. In $(E-$ 1) $\mathrm{Cl}$, radical cations form weakly dimerized stacks, as confirmed by the temperature dependence of the magnetic susceptibility and the weak conductivity $\left(\sigma_{\mathrm{RT}}=4.8 \times 10^{-5} \mathrm{~S} \mathrm{~cm}^{-1}\right)$.

\section{Experimental Section}

\section{General considerations}

Reagents were obtained from commercial suppliers and used without further purification. Acetonitrile, dichloromethane, methanol, THF, and toluene were dried using commercial solvent purification system from Inert Technology. NMR spectra were recorded on Bruker Avance $400 \mathrm{MHz}$ spectrometer. Spectra were recorded in chloroform-d and referenced to residual $\mathrm{CHCl}_{3}\left({ }^{1} \mathrm{H}, 7.26 \mathrm{ppm}\right)$ or $\mathrm{CDCl}_{3}\left({ }^{13} \mathrm{C}, 77.2 \mathrm{ppm}\right)$. Chemical shifts $(\delta)$ are reported in ppm and coupling constants $(J)$ are reported in $\mathrm{Hz}$. The following abbreviations are used to describe multiplicity; s-singlet, ddoublet, t-triplet, q-quartet, m-multiplet. HRMS experiments were carried out on a Waters Q-Tof 2 (ESI-Electrospray Ionization, ASAP-Atmospheric Solids Analysis Probe) spectrometer. Analytical TLC was carried out on Merck $60 \mathrm{~F}_{245}$ aluminium backed silica gel plates. Compounds were purified by flash column chromatography using Geduran ${ }^{\circledR}$ silica gel 60 (0.040-0.063 nm). Cyclic voltammetry measurements were carried out in a one-compartment cell under argon, equipped with a platinum wire, a glassy carbon, and a Saturated Calomel Electrode (SCE) as working, counter, and reference electrodes, respectively, using a Bio-Logic SP-50 potentionstat. Analyte solutions $\left(10^{-3} \mathrm{M}\right.$ solution of compound) were prepared in $0.1 \mathrm{M}$ solutions of $\left(\mathrm{NBu}_{4}\right)\left(\mathrm{PF}_{6}\right)$ in $\mathrm{CH}_{2} \mathrm{Cl}_{2}$.

\section{Synthesis of $\operatorname{TTF}(\mathrm{SMe})_{2} \mathrm{l}_{2}(1)$}

To a yellow solution of $(Z, E)-2,6(7)$-bis(methylthio)tetrathiafulvalene (BMTTTF) $(540 \mathrm{mg}, 1.8 \mathrm{mmol})$ in THF $(50 \mathrm{~mL})$, was added dropwise at $-80{ }^{\circ} \mathrm{C}$ a THF solution of lithium diisopropylamide $(2 \mathrm{M}, 4.5 \mathrm{~mL}, 9 \mathrm{mmol})$. After stirring at $-80^{\circ} \mathrm{C}$ for $3 \mathrm{~h}$, the slightly yellow suspension was treated with iodoperfluorohexane $(1.0 \mathrm{~mL}, 9.1 \mathrm{mmol})$. The mixture was slowly warmed to ambient temperature and stirred overnight. The reaction mixture was quenched with water $(50 \mathrm{~mL})$ and the organic layer was extracted with dichloromethane $(3 \times 50 \mathrm{~mL})$ and the combined organic extracts were dried over magnesium sulfate, filtered, and concentrated under reduced pressure. The red residue was purified by flash chromatography on silica gel to afford a red solid. Recrystallization from hot EtOAc $\left(150 \mathrm{~mL}, 60{ }^{\circ} \mathrm{C}\right)$ afforded 1 as red needle-like crystals (590 mg, 60\%). [Column conditions: silica cartridge $4 \mathrm{~g}$ (Serlabo); solid deposit on Celite $\AA$; $\lambda_{\text {detection: }}(254 \mathrm{~nm}$, $320 \mathrm{~nm}$ ); $\mathrm{CH}_{2} \mathrm{Cl}_{2}$ in petroleum ether at $30 \mathrm{~mL} / \mathrm{min}$ (15 $\mathrm{min} / 5 \% ; 30 \mathrm{~min} /$ 10\%); collected fraction: 5-30 min]. ${ }^{1} \mathrm{H}$ NMR (300 MHz, CDCl 3$) \delta 2.42$ (2xs, 6H). ${ }^{13} \mathrm{C}$ NMR (75 MHz, $\left.\mathrm{CDCl}_{3}\right) \delta 130.7$ (C), $77.2(\mathrm{C}), 71.6(\mathrm{C}), 19.3(\mathrm{Me})$. HRMS $\left(\mathrm{ESI}^{+}, \mathrm{MeOH} / \mathrm{CH}_{2} \mathrm{Cl}_{2}, 50 / 50\right.$ ) calculated for $\mathrm{C}_{8} \mathrm{H}_{6} \mathrm{l}_{2} \mathrm{~S}_{6}\left[\mathrm{M}^{+}\right] \mathrm{m} / \mathrm{z}$ 547.68779, found: 547.6882. The full NMR spectra are presented in the supporting information and the ${ }^{1} \mathrm{H}$ NMR and MS characterizations were consistent with the reported data for this compound. ${ }^{14}$

\section{Electrocrystallization}

$1(10 \mathrm{mg}$ ) was oxidized on a Pt electrode (length $2 \mathrm{~cm}$, diameter $1 \mathrm{~mm}$ ) at a constant current of $2 \mu \mathrm{A}$ in an $\mathrm{EtOH}(96 \%)$ solution $(10 \mathrm{~mL})$ of $\mathrm{Bu} 4 \mathrm{NCl}$ as electrolyte at $40{ }^{\circ} \mathrm{C}$. After 10 days, black needle-like crystals of $(E-1) \mathrm{Cl}$ were harvested from the anodic compartment of the electrochemical cell and washed with cold $\mathrm{EtOH}$. The bulk purity of the polycrystalline samples was confirmed by powder X-ray diffraction (Figure S2). Other electrocrystallization experiments were conducted with the $\mathrm{Bu}_{4} \mathrm{~N}^{+}$salts of $\mathrm{Br}^{-}, \mathrm{I}^{-}, \mathrm{I}_{3}^{-}, \mathrm{SCN}^{-},\left[\mathrm{Ag}(\mathrm{CN})_{2}\right]^{-}, \mathrm{ClO}_{4}^{-}, \mathrm{ReO}_{4}^{-}, \mathrm{HSO}_{4}^{-}, \mathrm{PF}_{6}^{-}$and $\mathrm{AsF}_{6}^{-}$, without success for isolating single crystalline materials.

\section{Crystallographic data}

Details about data collection and solution refinement are given in Table 3. $X$-ray diffraction measurements were performed on a Bruker Kappa CCD diffractometer for 1 and on a Bruker APEX II diffractometer for $(E-1) C l$, both operating with a Mo Ka $(\lambda=0.71073 \AA)$ X-ray tube with a graphite monochromator. The structures were solved (SHELXS-97) by direct methods and refined (SHELXL-97) by full-matrix least-squares procedures 
on $\mathrm{F}^{2} .{ }^{32}$ All non- $\mathrm{H}$ atoms of the donor molecules were refined anisotropically, and hydrogen atoms were introduced at calculated positions (riding model), included in structure factor calculations but not refined. Owing to the low quality of the $(E-1) C l$ crystal, the EADP restraints were used for ( $\mathrm{C} 1 \mathrm{C} 2 \mathrm{C} 3 \mathrm{C} 5 \mathrm{C} 6 \mathrm{C} 7)$ and $(\mathrm{C} 4 \mathrm{C} 8)$. Note that the suggestion (checkcif $\mathrm{B}$ alert) of an alternative $\mathrm{C}$-centered symmetry for the structure of $(E-1) \mathrm{Cl}$, based on the examination of the atomic coordinates, was not retained as a careful analysis of the systematic absences clearly shows a primitive lattice type (with $\mathrm{h}+\mathrm{k}=2 \mathrm{n}+1$ reflections not extinct). Deposition Numbers 1993684 (for 1), 1993685 (for $(E-1) C l$ ), contain the supplementary crystallographic data for this paper. These data are provided free of charge by the joint Cambridge Crystallographic Data Centre and Fachinformationszentrum Karlsruhe Access Structures service www.ccdc.cam.ac.uk/structures.

Table 3. Crystallographic data.

\begin{tabular}{|c|c|c|}
\hline Compound & 1 & $(E-1) \mathrm{Cl}$ \\
\hline Formula & $\mathrm{C}_{8} \mathrm{H}_{6} \mathrm{l}_{2} \mathrm{~S}_{6}$ & $\mathrm{C}_{8} \mathrm{H}_{6} \mathrm{l}_{2} \mathrm{~S}_{6} \mathrm{Cl}$ \\
\hline Formula moiety & $\mathrm{C}_{8} \mathrm{H}_{6} \mathrm{l}_{2} \mathrm{~S}_{6}$ & $\mathrm{C}_{8} \mathrm{H}_{6} \mathrm{I}_{2} \mathrm{~S}_{6}, \mathrm{Cl}$ \\
\hline $\mathrm{FW}\left[\mathrm{g} \cdot \mathrm{mol}^{-1}\right]$ & 548.29 & 583.74 \\
\hline System & monoclinic & monoclinic \\
\hline Space group & $\mathrm{P} 21 / \mathrm{C}$ & $\mathrm{P} 2 / \mathrm{n}$ \\
\hline a $[\AA]$ & $4.4004(4)$ & $12.4178(15)$ \\
\hline $\mathrm{b}[\AA]$ & $14.6309(13)$ & $16.781(2)$ \\
\hline$c[\AA]$ & $11.9271(9)$ & $7.7346(10)$ \\
\hline$\alpha$ [deg] & 90.00 & 90.00 \\
\hline$\beta$ [deg] & $96.572(6)$ & $99.495(5)$ \\
\hline Y [deg] & 90.00 & 90.00 \\
\hline $\mathrm{V}\left[\AA^{3}\right]$ & $762.84(11)$ & $1589.6(3)$ \\
\hline $\mathrm{T}[\mathrm{K}]$ & $293(2)$ & $150(2)$ \\
\hline Z & 2 & 4 \\
\hline Crystal size $\left[\mathrm{mm}^{3}\right]$ & $0.12 \times 0.03 \times 0.02$ & $0.10 \times 0.02 \times 0.01$ \\
\hline$D_{\text {calc }}\left[\mathrm{g} . \mathrm{cm}^{-1}\right]$ & 2.387 & 2.439 \\
\hline$\mu\left[\mathrm{mm}^{-1}\right]$ & 4.915 & 4.888 \\
\hline Total refls & 7113 & 10811 \\
\hline$\theta_{\max }\left[{ }^{\circ}\right]$ & 30.452 & 27.516 \\
\hline Abs corr & multi-scan & multi-scan \\
\hline$T_{\min }, T_{\max }$ & $0.838,0.906$ & $0.891,0.953$ \\
\hline Uniq. refls & 2300 & 3520 \\
\hline $\mathrm{R}_{\text {int }}$ & 0.0644 & 0.0713 \\
\hline Uniq. refls $(I>2 \sigma(I))$ & 1123 & 1813 \\
\hline $\mathrm{R}_{1}$ & 0.0525 & 0.1411 \\
\hline$w R_{2}$ (all data) & 0.1104 & 0.3798 \\
\hline GOF & 0.989 & 1.203 \\
\hline
\end{tabular}

Res. dens. $\left[\mathrm{e} \AA^{-3}\right] \quad 0.73,-0.59 \quad 3.15,-2.336$

\section{Theoretical calculations}

Geometry optimizations with Density Functional Theory calculations were carried out using the Gaussian 09 Revision D.01 software, the B3LYP functional and the $6-31+G^{* *}$ basis set for all atoms and the LANLdp basis set for iodine. GaussView 5.0.9 was used to generate the figures.

\section{Transport and magnetic measurements}

The two-point dc resistivity measurements were carried out using a Quantum Design PPMS system. The measurements were performed on polycrystalline samples pressed with a home-built screw cell (typically 3 $\mathrm{mm}$ diameter and $0.5 \mathrm{~mm}$ thickness). Magnetic measurements were performed with a MPMS Quantum Design SQUID magnetometer. Reproducible measurements were performed on polycrystalline samples of $(E-1) \mathrm{Cl}(31.8 \mathrm{mg})$, that are introduced in a sealed polypropylene bag $(14.18 \mathrm{mg})$. Prior to measurements, the field-dependent magnetization was measured in order to confirm the absence of any bulk ferromagnetic impurities. DC susceptibility data were corrected for diamagnetic contributions from the sample holder and for the core diamagnetism of each sample.

\section{Acknowledgements}

This research was supported by the French National Research Agency Grant, ANR 17-ERC3-0003, the Campus France PHC STAR 41595RK, the financial help for the acquirement of the scientific equipment (AES) from Rennes Metropole and a PhD grant (to M. Beau) from région Bretagne. S. Lee thanks the National Research Foundation of Korea (NRF2018K1A3A1A21043478. We thank Dr. Y. Kiyota (Dpt. Org. Polym. Mater., TITech, Japan) for preliminary experiments. This work was granted access to the HPC resources of CINES under the allocation $2020-\mathrm{A} 0080805032$ made by GENCI.

Keywords: chalcogen bonding $\bullet$ crystal engineering $\bullet$ halogen bonding $\bullet$ sigma-hole interactions $\bullet$ tetrathiafulvalenes

[1] G. Cavallo, P. Metrangolo, R. Milani, T. Pilati, A. Priimagi, G. Resnati, G. Terraneo, Chem. Rev. 2016, 116, 2478-2601.

[2] M. Fourmigué, P. Batail, Chem. Rev. 2004, 104, 5379-5418.

[3] T. Imakubo, H. Sawa, R. Kato, Synth. Metals 1995, 73, 117-122.

[4] a) J. Nishijo, E. Ogura, J. Yamaura, A. Miyazaki, T. Enoki, T. Takano T, Y. Kuwatani, M. Iyoda, Solid State Commun. 2000, 116, 661-664; b) T. Devic, B. Domercq, P. Auban-Senzier, P. Molinié, M. Fourmigué. Eur. J. Inorg. Chem. 2002, 2844-2849.

[5] R. Oliveira, S. Groni, C. Fave, M. Branca, F. Mavré, D. Lorcy, M. Fourmigué, B. Schöllhorn, Phys. Chem. Chem. Phys. 2016, 18, 1586715873.

[6] J. Lieffrig, O. Jeannin, A. Frąckowiak, I. Olejniczak, R. Świetlik, S. Dahaoui, E. Aubert, E. Espinosa, P. Auban-Senzier, M. Fourmigué, Chem. Eur. J. 2013, 19, 14804-14813.

[7] A. Frackowiak, I. Olejniczak, R. Swietlik, O. Jeannin, M. Fourmigué, J. Phys. Chem. C 2016, 120, 23740-23747.

[8] A. Frąckowiak, R. Świetlik, L. Maulana, D. Liu, M. Dressel, O. Jeannin, M. Fourmigué, J. Phys. Chem. C. 2020, 124, 10, 5552-5558.

[9] A. S. Batsanov, M. R. Bryce, A. Chesney, J. A. K. Howard, D. E. John, A. J. Moore, C. L. Wood, H. Gershtenman, J. Y. Becker, V. Y. Khodorkovsky, A. Ellern, J. Bernstein, I. F. Perepichka, V. Rotello, M. Gray, A. O. Cuello. J. Mater. Chem. 2001, 11, 2181-2191; Y. Nakano, Y. 
Takahashi, K. Ishida, M. Ishikawa, H. Yamohi, M. Uruichi, Mater. Chem. Front. 2018, 2, 752.

[10] A. Ranganathan, A. El-Ghayoury, C. Mézière, E. Harté, R. Clérac, P. Batail. Chem. Commun. 2006, 2878-2880.

[11] E. Fanghänel, L. van Hinh, G. Schukat, J. Patzsch, J. Prakt. Chem. 1989, 331, 479-485.

[12] a) A. Souizi, A. Robert, P. Batail, L. Ouahab, J. Org. Chem. 1987, 52, 1610-1611; b) M. Giffard, P. Frère, A. Gorgues, A. Riou, J. Roncali, L. Toupet, J. Chem. Soc., Chem. Commun. 1993, 944-945.

[13] O. Jeannin, E. Canadell, P. Auban-Senzier, M. Fourmigué, Chem. Commun. 2016, 52, 308-311.

[14] E. Wang, H. Li, Hongxiang; W. Hu, D. Zhu, J. Polym Sc. A 2006, 44 2707-2713.

[15] A. Bondi, J. Phys. Chem. 1964, 68, 441-451.

[16] G. Cavallo, P. Metrangolo, T. Pilati, G. Resnati, M. Sansotera, G. Terraneo, Chem. Soc. Rev. 2010, 39, 3772-3783.

[17] E. M. Foyle, N. G. White, CrystEngComm 2020, 22, 2526-2536.

[18] T. Imakubo, M. Kobayashi, Eur. J. Inorg. Chem. 2014, 3973-3981.

[19] T. Imakubo, T. Shirahata, K. Herve, L. Ouahab, J. Mater. Chem. 2006, 16, 162-173.

[20] J. Lieffrig, R. Le Pennec, O. Jeannin, P. Auban-Senzier, M. Fourmigué, CrystEngComm 2013, 15, 4408-4412.

[21] a) P. Scilabra, G. Terraneo, G. Resnati, Acc. Chem. Res. 2019, 52, 13131324; (b) N. Biot, D. Bonifazi, Coord. Chem. Rev. 2020, 413, 213243; c) K. T. Mahmudov, M. N. Kopylovich, M. F. C. Guedes da Silva, A. J. L. Pombeiro, Dalton Trans. 2017, 46, 10121-10138; d) S. Benz, J. LópezAndarias, J. Mareda, N. Sakai, S. Matile, Angew. Chem. Int. Ed. 2017 56, 812-815; e) L. Vogel, P. WOnner, S. M. Huber, Angew. Chem. Int. Ed. 2019, 58, 1880-1891; f) V. Kumar, Y. Xu, D. L. Bryce, Chem. Eur. J. 2020, 26, 3275-3286.

[22] R. P. Shibaeva, L. P. Rozenberg, A. F. Shestyakov, T. A. Khannanova, Zh. Strukt. Khim. 1991, 32, 98-101.

[23] L. V. Zorina, S. V. Simonov, S. S. Khasanov, R. P. Shibaeva, J. Low Temp. Phys. 2011, 37, 744-748.

[24] M. Fourmigué, E. W. Reinheimer, A. Assaf, O. Jeannin, A. Saad, Inorg. Chem. 2011, 50, 4171-4181.

[25] M. Fourmigué, E. W. Reinheimer, K. R. Dunbar, P. Auban-Senzier, C. Pasquier, C. Coulon, Dalton Trans. 2008, 4652-4658.

[26] a) M. J. Rosseinsky, M. Kurmoo, D. R. Talham, P. Day, D. Chasseau, D. Watkin, Chem. Commun. 1988, 88-90; b) R. M. Lobkovskaya, R. P. Shibaeva, E. E. Laukhina, A. V. Zvarykina, Zh. Strukt. Khim. 1990, 31, 3-5.

[27] B. Zhang, Y. X. Yao, D. B. Zhu, Synth. Metals 2001, 120, 671-674.

[28] M. B. Hursthouse, S. J. Coles, S. Turner, CSD Communication (Private Communication) 2003.

[29] a) R. Williams, C. L. Ma, S. Samson, S. K. Khanna, R. B. Somoano, J. Chem. Phys. 1980, 72, 3781-3788; b) B. A. Scott, S. J. La Placa, J. B. Torrance, B. D. Silverman, B. Welber. J. Am. Chem. Soc. 1977, 99, 6631-6639.

[30] X.-W. Xiao, W. Xu, H. Xu, D.-Q. Zhang, D.-B. Zhu, Acta Crystallogr. E 2005, 61, 0111.

[31] R. Oliveira, S. Groni, A. Vacher, F. Barrière, D. Lorcy, M. Fourmigué, E. Maisonhaute, B. Schöllhorn, C. Fave, ChemistrySelect 2018, 3, 88748880.

[32] Sheldrick, G. M. Programs for the Refinement of Crystal Structures; University of Göttingen: Göttingen, Germany, 1996. 
WILEY-VCH

\section{FULL PAPER}

\section{Entry for the Table of Contents}

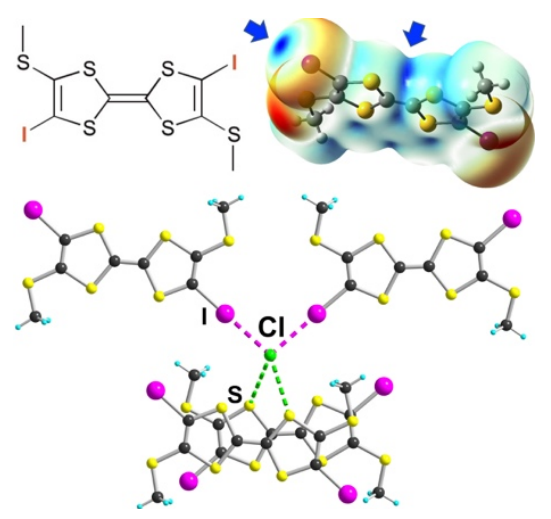

Strong and simultaneous halogen $(\mathrm{XB})$ and chalcogen $(\mathrm{ChB})$ bonding interactions are identified in the $1: 1$ salt of a diiodotetrathiafulvalene salt with $\mathrm{Cl}^{-}$anion. Electrostatic potential calculations on the cation radical further demonstrate the efficient activation of the sulfur atoms of the 1,3-dithiole rings, as strong as with the iodine atoms. The radical cations form weakly dimerized stacks, as confirmed by the variable-temperature magnetic susceptibility and the weak conductivity. 